\title{
Analysis of US Renewable Fuels Policies Using a Modified MARKAL Model*
}

\author{
Kemal Sarica \\ Wallace E. Tyner \\ Purdue University
}

\begin{abstract}
This paper evaluates the impacts of alternative renewable fuels policies using a bottom-up energy technology model, MARKAL, enhanced with data generated from a global general equilibrium model, GTAP. MARKAL does not do a good job of handling biofuels because the cost of producing biofuels depends where one is on the land supply curve, and MARKAL contains no land data or parameters. Agricultural land data from GTAP was added to MARKAL by agro-ecological zone. GTAP was then simulated in increments of one billion gallons of corn ethanol up to 20 billion gallons. The land rent values obtained from these simulations were used to produce land supply curves for MARKAL thereby permitting MARKAL to reliably simulate biofuels development in the context of other energy technologies.
\end{abstract}

The main results are as follows:

- Little or no biofuels would be produced in the absence of the RFS and all subsidies. Some corn ethanol would be produced without RFS or subsidies, but less than current production.

- No cellulosic biofuels would be produced without government incentives.

- Production of cellulosic ethanol is not attractive even under the volumetric subsidy regime.

- The subsidy costs vary widely depending on the subsidy used and whether or not the coal/biomass thermochemical technology is enabled.

- Coal combined thermochemical pathway with biomass is cheaper than biomass alone.

- The subsidy costs and costs of the RFS also vary depending on what is happening with development of other energy technologies. Quantification of this effect is possible only with a bottom-up energy model like MARKAL.

Key words: MARKAL, GTAP, biofuels policy, energy policy

*This paper uses GTAP data base version 6 based on 2001 data. We intend to update to the version 7 data (2004) as soon as some data errors and inconsistencies have been corrected in the newer version. 


\title{
Analysis of US Renewable Fuels Policies Using a Modified MARKAL Model
}

\author{
Kemal Sarica \\ Wallace E. Tyner \\ Purdue University
}

The United States has since 1978 promoted biofuels with a variety of subsidies (both state and federal) and now a Renewable Fuel Standard (RFS)(Tyner, 2008). The current RFS calls for 15 billion gallons of conventional biofuels, mainly corn based ethanol, by 2015 and 16 billion gallons of cellulosic biofuels by 2022. There have been many papers evaluating the consequences of US policies (subsidies and mandates) on corn prices, land use change, and other dimensions (Tyner, 2008; Tyner et al., 2010a; Tyner and Taheripour, 2008; Tyner et al., 2010b). However, prior research has not evaluated biofuels in the context of other energy options and has not generally quantified the costs of the US biofuels policies.

In this paper we make use of the US EPA MARKAL model to evaluate the impacts and costs of prospective US biofuels. The US EPA MARKAL model is a bottom up energy systems model that makes use of a detailed representation of energy technologies. Essentially a user specifies energy demand, and MARKAL allocates the demand to the lowest cost energy sources over time. Policies such as mandates, subsidies, carbon taxes, etc. also can be incorporated into the model.

In addition, we make significant modifications to the basic MARKAL data set and structure to take advantage of simulated data from the Global Trade Analysis Project (GTAP) model. We include in MARKAL the land use data for the US by agro-ecological zone (AEZ). More detail on the modifications is provided below. In essence, the modification enables us to have land supply curves in MARKAL that were generated in GTAP.

\section{The structure of the energy system model}

The family of the MARKAL models has been developed by the Energy Technology Systems Analysis Programme (ETSAP). The US EPA MARKAL model has been used for several national or international case studies (Hu and Hobbs, 2010; Sauthoff et al., 2010; Schafer and Jacoby, 2006). However, compared to other studies published before, this paper concentrates on biofuel subsidies and the Renewable Fuel Standard (RFS), technologies to reach the targets specified and the resulting effect on the energy system. For this purpose US EPA MARKAL has been modified to introduce the complete supply chain of biomass production regarding corn, corn stover, miscanthus and switchgrass, with the addition of land according to the Agro Ecological Zone (AEZ) classification system used in GTAP (Lee et al., 2005). In addition, model technologies for biofuels production have been updated based upon studies related to biochemical cellulosic ethanol (National Academy of Sciences, 2009) and thermo-chemical biomass conversion technologies (Kreutz et al., 2008).

The MARKAL modeling framework uses a reference energy system (RES) which represents currently available and possible future energy technologies and energy carriers and relations among them. Due to the large number of technologies and carriers it is not possible to cover all details of the RES in this paper. A simplified version of the RES used in the US EPA MARKAL model is depicted in Figure 1. The complete description of the RES used and other technical details in US EPA Model can be found in http://oaspub.epa.gov/eims/eimscomm.getfile?p_download_id=461323 (Carol Shay et al., 2006). In this 
analysis, a time horizon of 20 years (from 2010 to 2030) with 5-year time steps has been used. The currency unit used in this paper is US dollars for the year 2010.

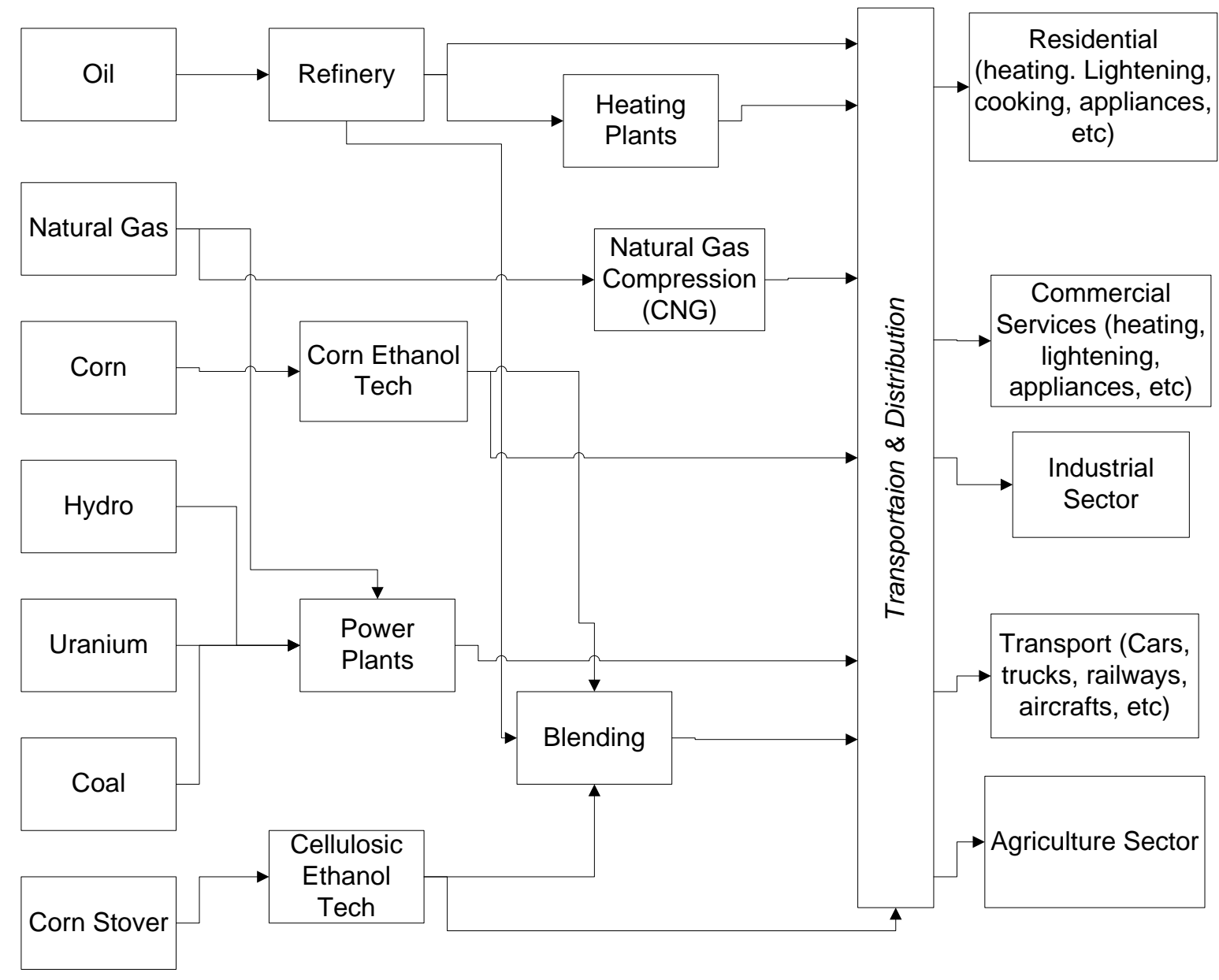

Figure 1 Simplified RES used US EPA MARKAL

\subsection{Model Modifications}

The approach for modeling of biomass production in the original US EPA MARKAL is similar to the approach used for modeling oil, natural gas, coal or hydraulic power production, where the production activity itself does not interfere with any other economic activity. No competition for another resource is present due to the production processes of coal, natural gas or uranium. You do not have to sacrifice production of oil to produce uranium or vice versa. In reality, use of land for biomass production itself interferes with the ongoing biomass production for crops, vegetables or any other related economic activities. In that sense the current US EPA MARKAL model or any national or international MARKAL model does not reflect this reality.

The introduction of land to the supply chain of corn, corn stover, switchgrass and miscanthus requires that a considerable amount of data be implemented in the MARKAL modeling framework. The land data came from the Global Trade Analysis Project (GTAP) database version 6 (Dimaranan, 2006). The GTAP land data is stratified into agro-ecological zones (AEZ), so it permitted us to introduce the yield levels by region. With these changes we have depicted the total supply chain of the selected biomass products. Land 
rent is now a part of the cost of producing biomass. In addition, we have introduced the most up to date seeding, harvesting, transport and harvesting costs for the feedstocks mentioned earlier.

Another modification of the US EPA MARKAL model that can be seen from Figure 2 is the coupling of corn production and corn stover production. The model can decide the level of stover production in conjunction with the corn grain production.

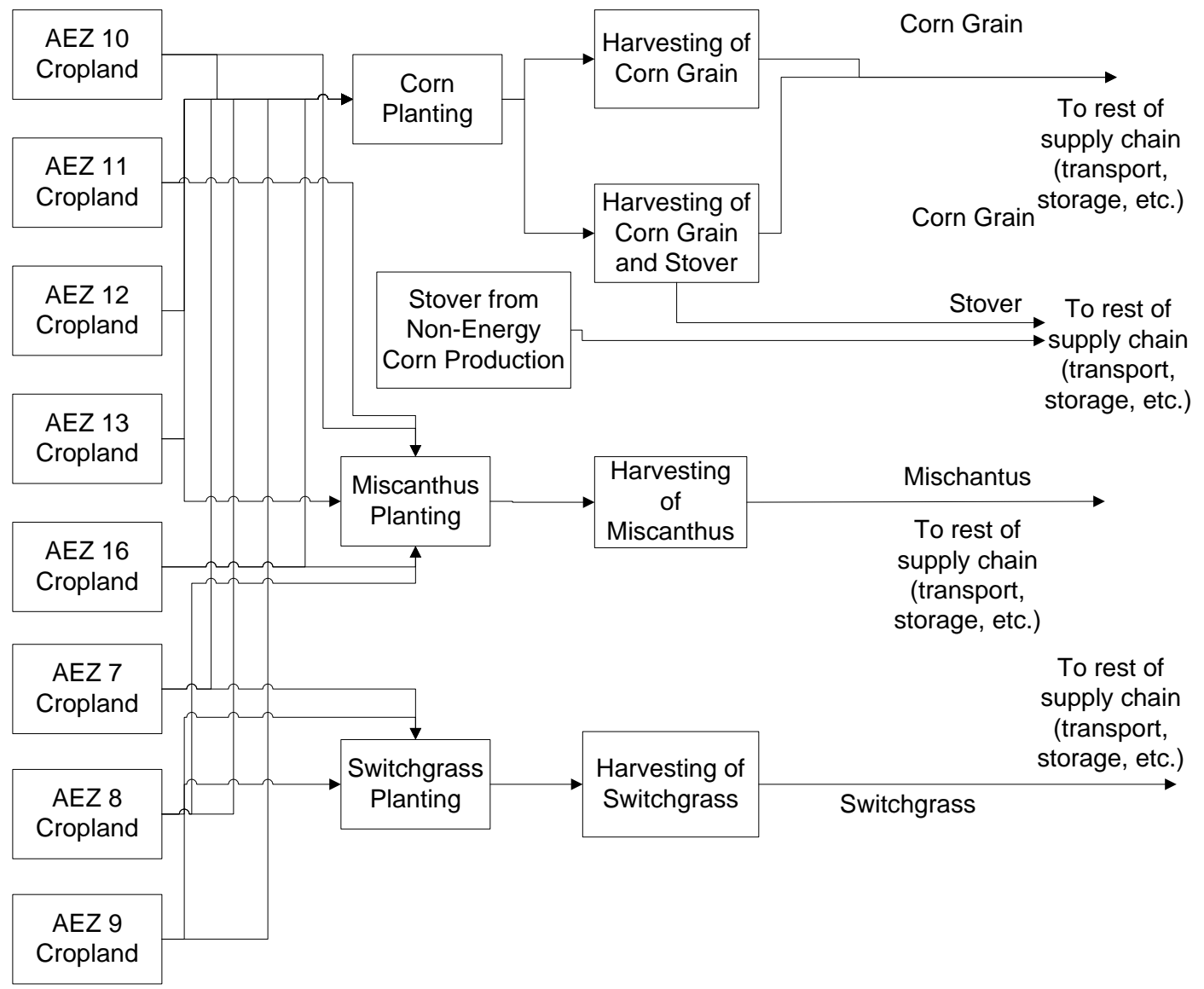

Figure 2 Placement of land in the supply chain of corn and energy crops.

Over the past few years we have witnessed a significant increase in the prices of corn and other agricultural commodities. Analysts sometimes speak in terms of a new normal for corn and other commodity prices. The new normal is lower than 2008 peaks but higher than historic norms. In the US, ethanol's share of corn production is about one-third. This added demand plus higher global demand and the fall of the US\$ has induced higher corn prices (Abbott et al., 2008; Abbott et al., 2009).

With higher commodity prices comes higher land rent, ceterus paribus. Land is the residual claimant so as incomes from land rise, so does the rent. In an attempt to capture this empirical fact of land rent being related to commodity prices and commodity prices having some link to the proportion of land used to supply ethanol plants, we have developed a stepped land supply function for corn into ethanol and other uses (Figures 3 and 4). This land supply curve was obtained by taking the results from GTAP simulations for corn ethanol in 1 billion gallon increments out to 20 billion gallons. There is no time dimension in those rent supply curves, since arable land area change due to external factors is beyond the scope of this 
paper. The aggregate supply curve in Figure 3 is the horizontal sum of the supply curves by AEZ in Figure 4. Since land rents would be correlated, we used the same slope for cropland pasture rent for miscanthus and switchgrass, but with the lower cropland pasture departure point.

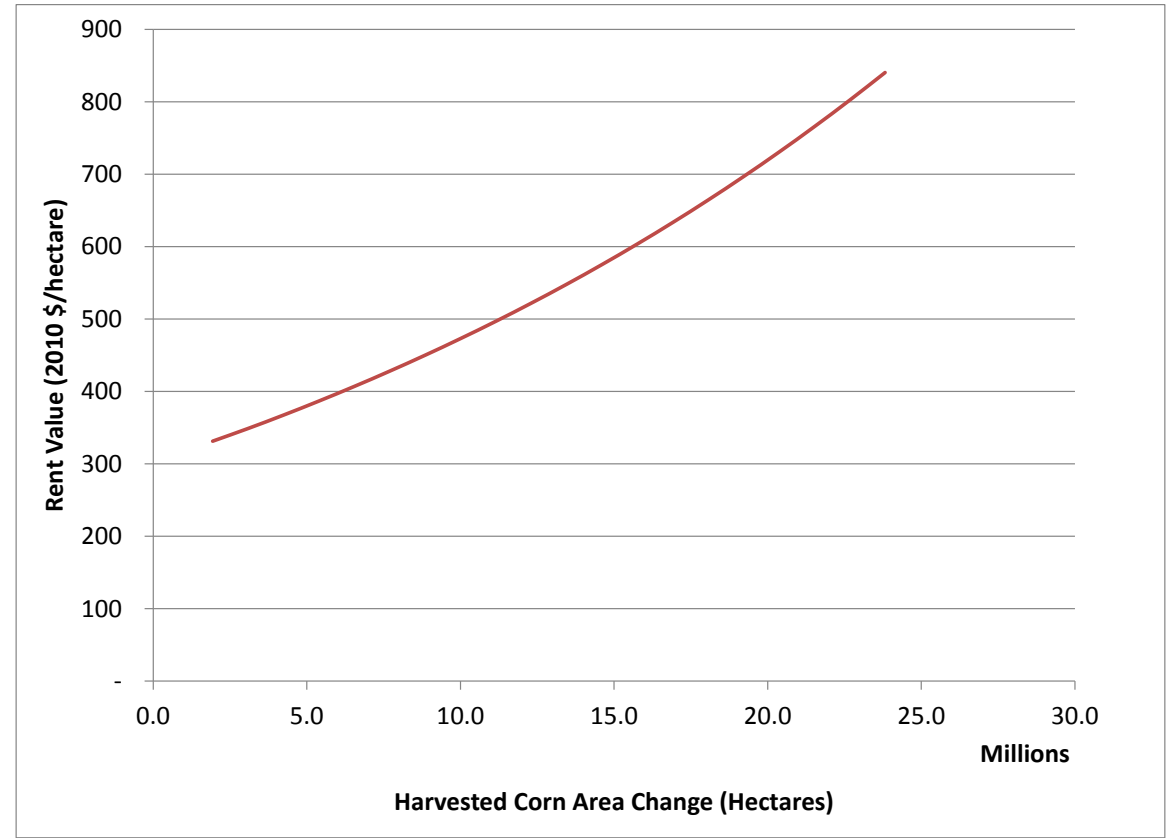

Figure 3 Land supply curve for combined land supply in modified US EPA MARKAL model

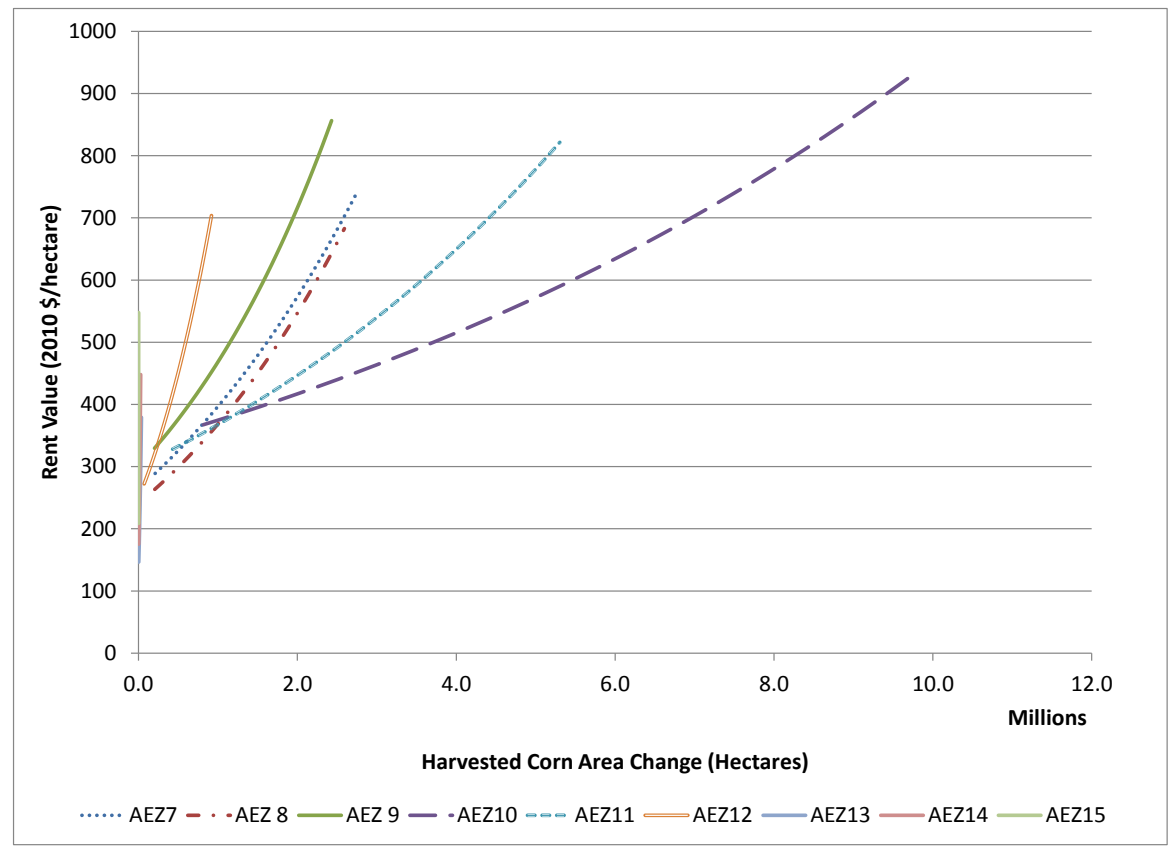

Figure 4 Land supply curve for each AEZ in modified US EPA MARKAL model 
A second set of changes involved updating the cellulosic ethanol production technologies present in the database using the detailed specifications given in National Academies study (National Academy of Sciences, 2009). The NAS study specified three scenarios for the improvement of the biochemical cellulosic ethanol production technologies, namely low, medium, and high. Low improvement can be deployed in the short term whereas medium improvement may be deployed in 2020. In this regard, we have introduced two technologies representing possible deployment for every biomass feedstock that can be used. Three biomass feedstocks are included for cellulosic ethanol production in this study: corn stover, switchgrass and miscanthus. Miscanthus and switchgrass are deployed in one technology due to very similar chemical structure. We followed the National Academy study by selecting the 40 million gallon per year capacity to be used in the modified US EPA MARKAL model. Table 1 displays the parameters for the technologies.

The third set of changes is the introduction of thermochemical technologies for processing of biomass into the modified US EPA MARKAL model. Detailed technology description and cost analysis has been carried out by Kreutz and colleagues (Kreutz et al., 2008). Those designs are mainly based on synthesis of Fischer-Tropsch liquids (FTL). In their analysis they claim that FTL are attractive for biomass based fuel production since FTL offers as advantages over cellulosic ethanol the prospects that: (i) no significant transportation fuel infrastructure changes would be required for widespread use; (ii) it can probably accommodate more easily the wide range of biomass feedstocks that are likely to characterize the lignocellulosic biomass supply_-because gasification-based processes tend to more tolerant of feedstock heterogeneity than biochemical processes. We selected the two most promising designs to be introduced into the modified US EPA MARKAL model. First, use of coal with biomass with carbon sequestration and storage (CCS) technology, which is promising since it makes the use of cheap coal resources with biomass use and reduces carbon emissions for a relatively low price. Second is direct use of biomass throughout the thermochemical process without CCS support. Both of the designs offer zero carbon emissions. This important property of the selected designs makes them a competitive alternative to the cellulosic ethanol production choices for RFS targets. Table 2 displays the parameters describing the thermochemical technologies introduced into the model. Electricity produced from those technologies is included in energy systems analysis.

Table 1 Parameters regarding the cellulosic ethanol production technologies

\begin{tabular}{|c|c|c|c|c|c|}
\hline & Units & $\begin{array}{l}\text { Cellulosic Ethanol } \\
\text { from Stover, } 2010\end{array}$ & $\begin{array}{l}\text { Cellulosic Ethanol } \\
\text { from Stover, } 2020\end{array}$ & $\begin{array}{l}\text { Cellulosic Ethanol } \\
\text { from Crops, } 2010\end{array}$ & $\begin{array}{l}\text { Cellulosic Ethanol } \\
\text { from Crops, } 2020\end{array}$ \\
\hline $\begin{array}{l}\text { Investment Cost } \\
\text { Operating \& }\end{array}$ & $\begin{array}{l}2010 \$ / \text { liter / } \\
\text { year }\end{array}$ & 1.71 & 1.49 & 1.90 & 1.65 \\
\hline Maintenance & $2010 \$ /$ liter & 0.35 & 0.28 & 0.40 & 0.32 \\
\hline Life & \# of year & 30 & 30 & 30 & 30 \\
\hline Input & $\begin{array}{l}\mathrm{kg} / \text { liter } \\
\text { gasoline }\end{array}$ & 5.32 & 4.61 & 5.71 & 4.95 \\
\hline Output: Ethanol & equivalent liter & 1 & 1 & 1 & 1 \\
\hline Output: Electricity & $k W h$ / liters & 0.51 & 0.63 & 0.96 & 1.18 \\
\hline Emission: $\mathrm{CO} 2$ & $\mathrm{~kg} /$ liter & 4.40 & 3.81 & 4.93 & 4.27 \\
\hline Available from & Year & 2010 & 2020 & 2010 & 2020 \\
\hline
\end{tabular}

Source: (National Academy of Sciences, 2009) 


\section{Results}

\subsection{Scenarios}

In this paper 10 scenario analyses have been completed. These scenarios are a combination of alternative policies and alternative technology choices. The ten scenarios are as follows:

1. No government interventions in biofuel markets (no RFS and no subsidies)

2. Biofuels RFS targets are implemented.

3. Biofuel subsidies only are implemented based on current legislation. Currently, the corn ethanol subsidy is 45 cents per gallon, and the cellulose biofuel subsidy (regardless of what biofuel) is \$1.01/gal. This scenario tests subsidies on a volumetric basis as at present (\$/gal.).

4. The subsidy for this case is based on energy content instead of volume. Cellulosic ethanol has a subsidy of $\$ 0.67$, whereas cellulosic bio-gasoline is at $\$ 1.01 / \mathrm{gal}$. Corn ethanol remains at $\$ 0.45 / \mathrm{gal}$.

5. The fifth scenario is a combination of the RFS and the energy based subsidy (2 and 4).

All five scenarios are run with biomass alone and biomass plus coal, which yield a total of ten scenarios. All subsidies are assumed to be constant in nominal terms.

Table 2. Descriptive parameters of the thermochemical technologies introduced to the model

\begin{tabular}{llrr} 
& & \multicolumn{2}{c}{ Biomass to FTL w/o } \\
\hline Investment Cost & Units & Coal + Biomass to FTL w/ CCS CCS & 3.24 \\
Operating \& Maintenance & 2010 / liter / year & 2.41 & 0.13 \\
Life & \# of year & 0.10 & 20 \\
Input: Coal & $\mathrm{kg} /$ liter & 20 & 6.87 \\
Input: Biomass & $\mathrm{kg} /$ liter & 1.90 & 1.00 \\
Output: Gasoline and Diesel & gasoline equivalent liter & 2.46 & 1.46 \\
Output: Electricity & $\mathrm{kWh} /$ liters & 1.00 & 5.50 \\
Emission: CO2 & $\mathrm{kg} /$ liter & 1.15 & \\
Emission: CO2 to CCS & $\mathrm{kg} /$ liter & 0.58 & 2015 \\
Available from & Year & 4.05 & 2015 \\
\hline Sources: & & & \\
\hline
\end{tabular}

Sources: (Kreutz et al., 2008; National Academy of Sciences, 2009)

\subsection{Scenario Outcomes}

Before the detailed presentation of the results it is useful to place them in context by providing the main energy sources for base case scenarios (Table 3), namely a scenario with no RFS target and subsidy.

Table 3 Main energy source prices in base case

\begin{tabular}{llrrrrr} 
& Unit & 2010 & 2015 & 2020 & 2025 & 2030 \\
\hline Electricity & 2000 \$ MWh & 78 & 75 & 72 & 76 & 82 \\
LPG & 2000 \$ Gallon & 0.62 & 0.63 & 0.58 & 0.58 & 0.59 \\
NGA & 2000 \$ thousand standard cubic feet & 574.3 & 552.4 & 565.1 & 588.6 & 622.7 \\
Diesel & 2000 / gallon & 0.74 & 0.74 & 0.83 & 0.87 & 0.83 \\
Gasoline & 2000 / gallon & 0.70 & 0.70 & 0.65 & 0.64 & 0.69 \\
Coal & 2000 / ton & 133.5 & 130.4 & 127.6 & 140.0 & 154.3 \\
Crude Oil & 2000 per barrel & 102.1 & 101.6 & 100.3 & 101.3 & 104.1 \\
\hline
\end{tabular}

Source: Authors' calculations based on model data. 


\subsubsection{Corn ethanol}

Since the main focus of this paper is cellulosic biofuels, we will spend more time reporting those results, but first we will briefly provide the results for corn ethanol. Corn ethanol is the first biofuel and currently one of the key biomass resources for the production of biofuels in US. We will report corn ethanol production for all scenarios (figure 5), and corn price (figure 6). The results for scenario one (no RFS and no subsidy) are as follows:

- Ethanol production falls from 2010 levels, but there is still corn ethanol production throughout the time period. It does not exceed 12 billion gallons in 2030, compared with 12 billion today.

- For scenario 2, the RFS only case, the RFS level is attained in all years.

- Scenarios 3 and 4 are the subsidy only cases. There are small differences in production levels between the energy equivalent and volumetric subsidy cases for cellulosic biofuels even though the corn ethanol subsidy remains at $\$ 0.45$. This is because of market interactions via corn stover with cellulosic biofuels. However, the differences are not large.

- When the RFS and subsidies are both applied, corn ethanol production exceeds the RFS level under most circumstances. This result is consistent with results we obtained in prior research using different modeling approaches (Tyner, 2008; Tyner and Taheripour, 2008; Tyner et al., 2010b).

- Corn ethanol prices are generally lowest when there is no RFS or subsidy as would be expected. There is no huge variation among the different subsidy options. Prices are generally highest in the presence of the RFS.

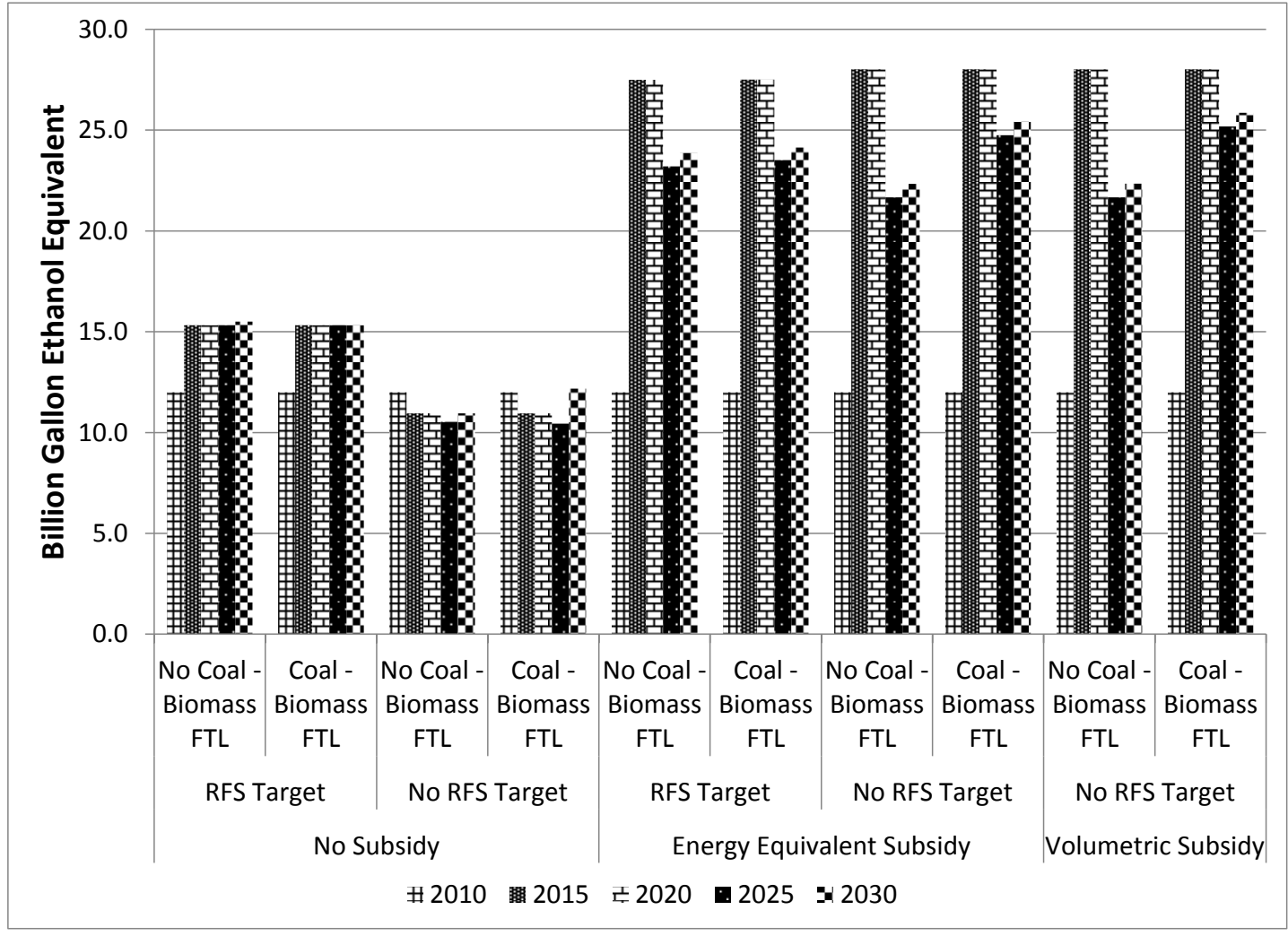

Figure 5 Corn Ethanol Production Levels for 2010-2030 period. 


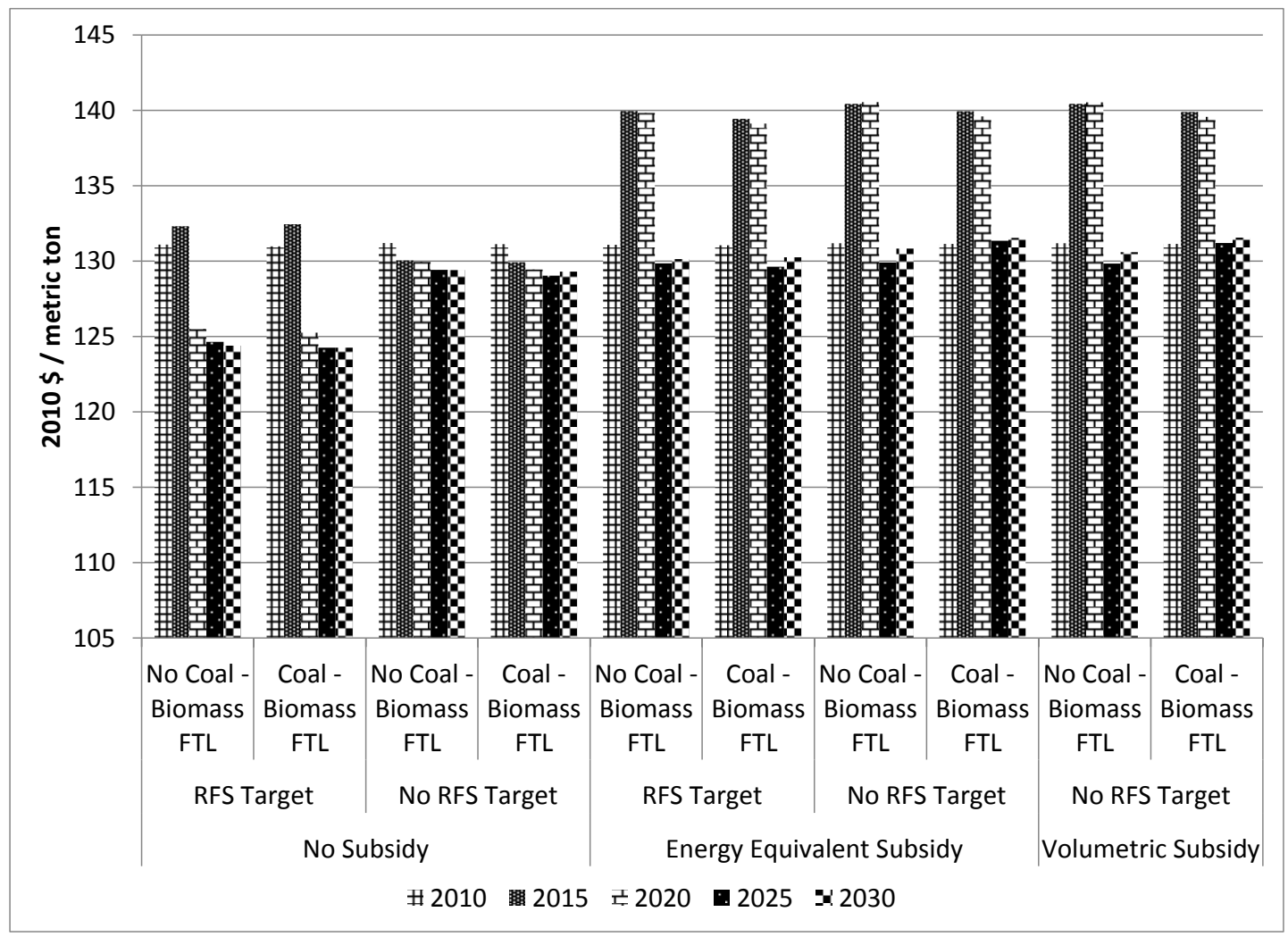

Figure 6 Corn prices under alternative scenario runs

Figure 7 contains the implicit tax/subsidy for the corn RFS over time and under the assumption of biomass only and biomass plus coal technologies being employed. The RFS is essentially a variable tax on consumers and subsidy to producers of corn ethanol with the amount of the tax/subsidy depending on the price of the fossil alternative and the others renewable fuels available in the market. The implicit tax/subsidy varies between 0 and 22 cents per gallon of ethanol depending on what alternative technologies are available, the oil price, and corn cost. The most dominant factor affecting the required subsidies is the relative price of gasoline which is very sensitive to the refinery capacity limits and production with respect to the demand pattern. Since the capacity expansion of refinery is a capital intensive operation, limited capacity leads to high prices due to increased imports, which lowers the required subsidies to support corn ethanol as in cases 2020 and 2030. 


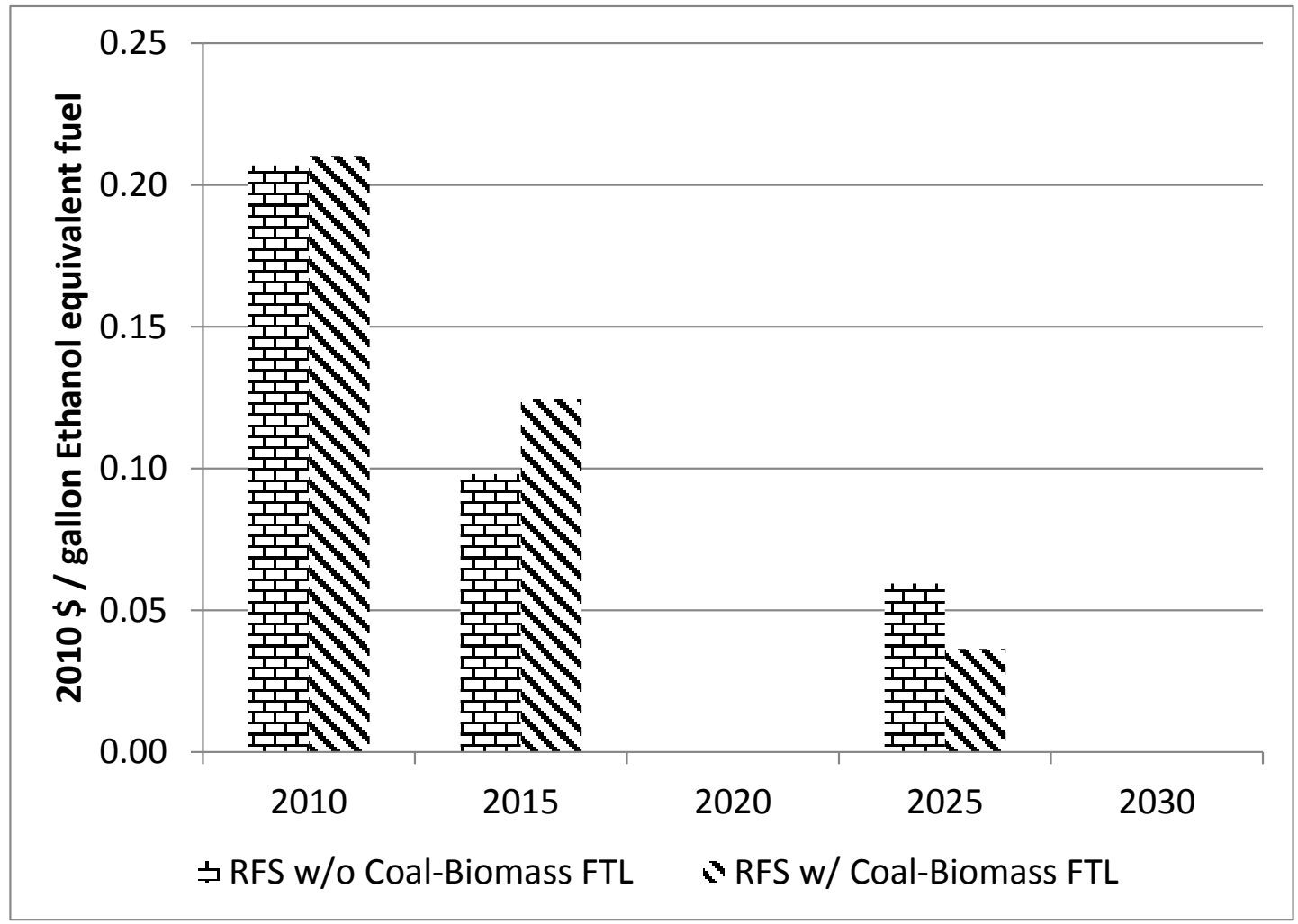

Figure 7 Corn ethanol RFS target shadow prices (required subsidies to reach target)

\subsubsection{Cellullosic biofuels}

The RFS for cellulosic biofuels reaches 16 billion gallons of ethanol equivalent by 2022. EPA has interpreted the RFS as ethanol equivalent, so one gallon of bio-gasoline counts as 1.5 gallons towards meeting the RFS. If all the 16 billion gallons of ethanol equivalent were satisfied with bio-gasoline, the volumetric standard would be 10.67 bil. gal. of bio-gasoline. There are two main conversion pathways for producing biofuels from cellulosic feedstocks. The biochemical pathway produces mainly ethanol, and the thermochemical pathway produces some mixture of bio-gasoline, green diesel, and other hydrocarbons. For this analysis, we assume that the hydrocarbon produced is bio-gasoline to keep the analysis manageable. We will present the results for cellulosic ethanol (biochemical pathway) first, and then turn to bio-gasoline via the thermochemical pathway. Figure 8 displays the cellulosic ethanol production levels under the different scenarios.

With no RFS and no subsidy, there is no production of cellulosic biofuel throughout the entire time period. With no RFS independent of the subsidy regime, no cellulosic ethanol production is observed throughout modeling time frame. This result suggests that even if with the medium term improvements mentioned, cellulosic fuel production via biochemical pathway cannot compete with the thermochemical alternative. 


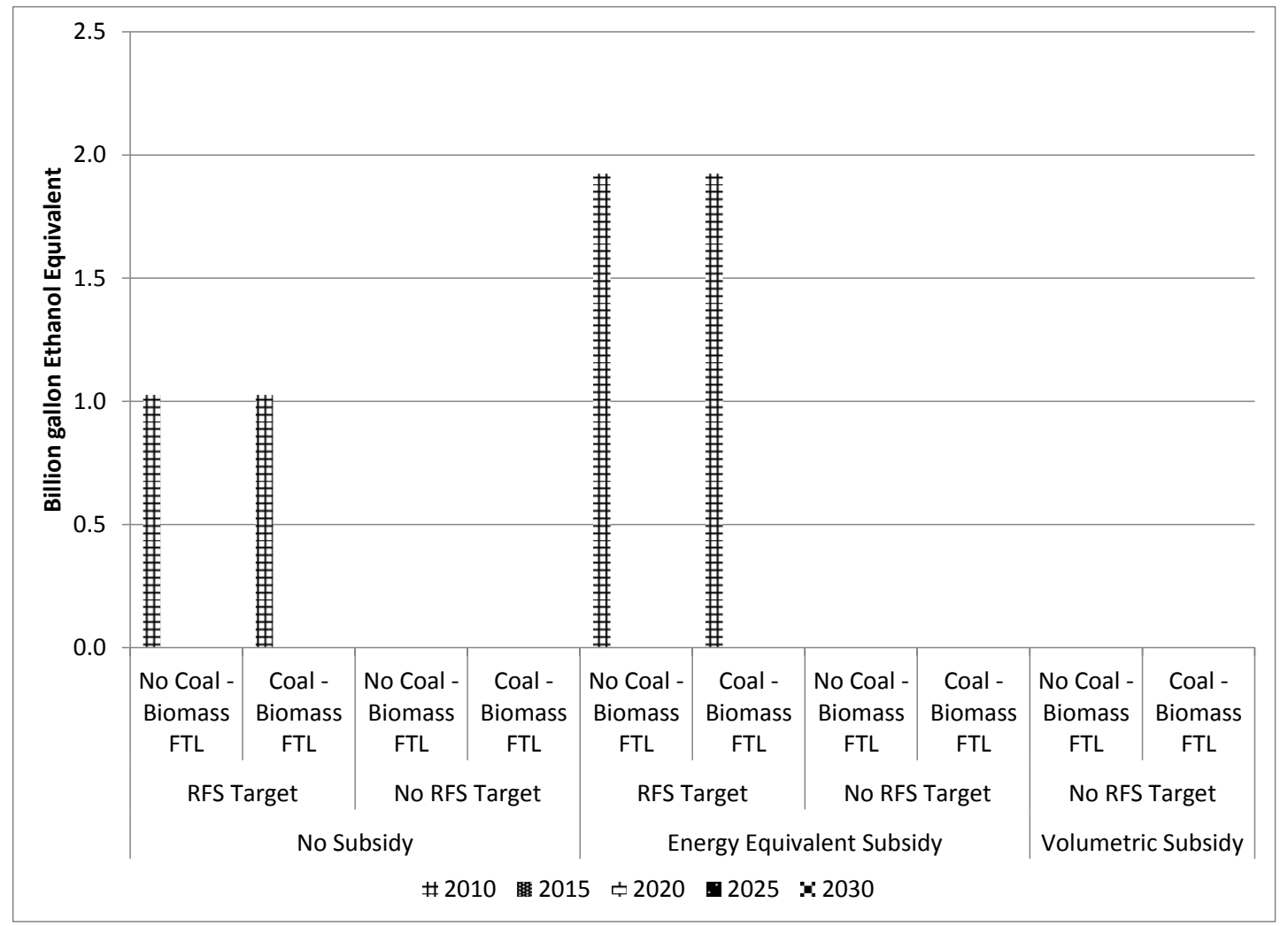

Figure 8 Cellulosic Ethanol production levels

Now we turn to cellulosic biofuel via the thermochemical production process (Figure 9). With no RFS and no subsidy, there is also no thermochemical biofuel production without coal-biomass thermochemical technology option. Coal-biomass technology offers around 1 billion gallons ethanol equivalent production from biomass. With no RFS and the volumetric subsidy, the biofuel production level grows to 13 bil. gal. after 2020 using the coal/biomass technology. With the energy equivalent subsidy, production grows to 11 bil. gal ethanol equivalent after 2020. In the absence of coal/biomass technology, production level stabilizes around 8 bil. gal. ethanol equivalent in the same time frame. The energy equivalent subsidy is more attractive for hydrocarbons produced via the thermochemical pathway.

Figure 10 contains the prices (marginal cost of production for the system) for thermochemical biofuels in $\$ /$ gal. gasoline equivalent. With the RFS in place, the prices are generally in the $\$ 2.40$ - $\$ 2.50$ range. With no RFS, the prices under energy equivalent subsidy scheme under no coal/biomass technology scenario are stable around $\$ 3.75 /$ gal. gasoline equivalent. With the availability of coal/biomass technology, the price for thermochemical fuels is around $\$ 2.80 /$ gal. gasoline equivalent independent of the subsidy policy. 


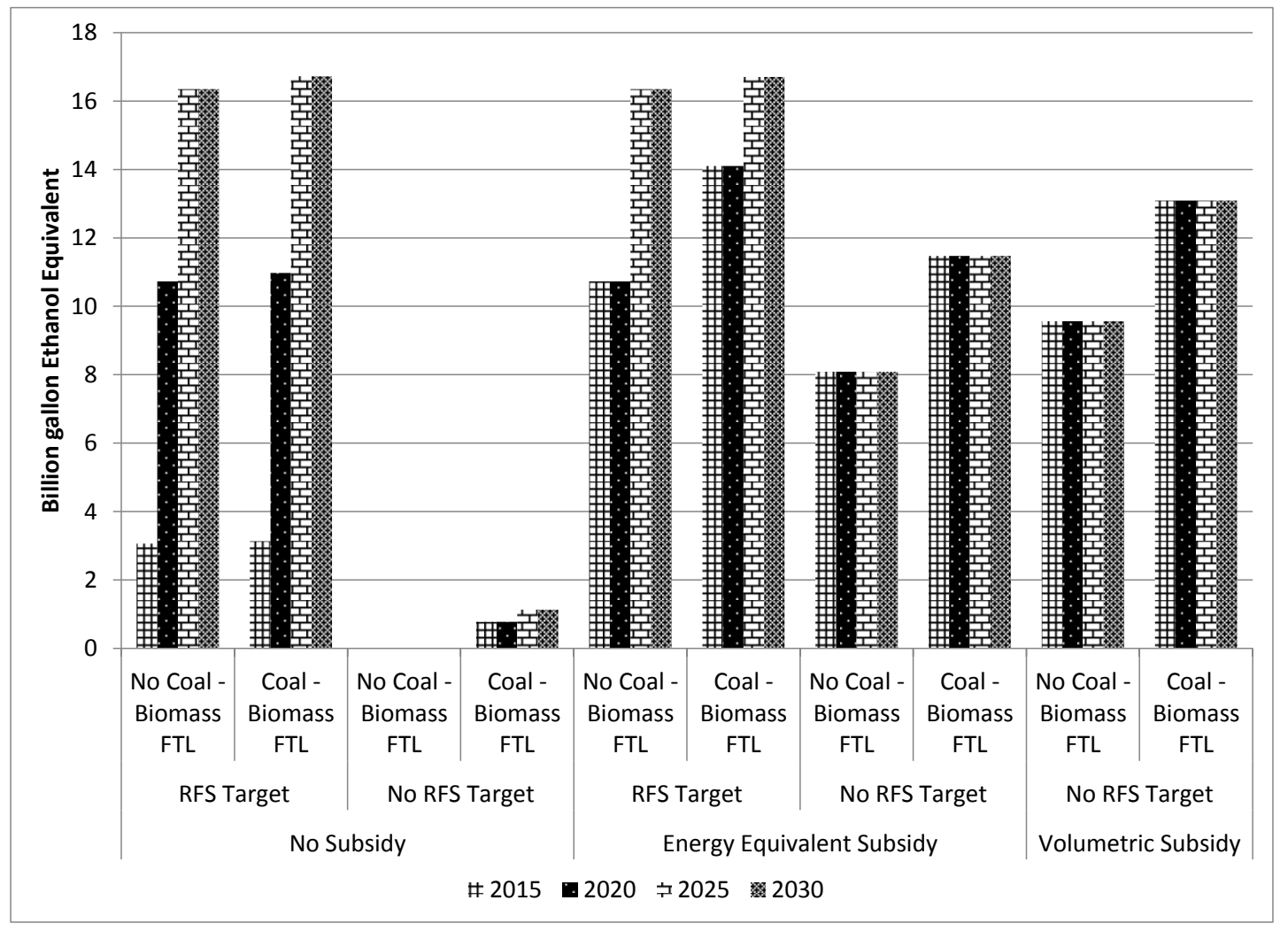

Figure 9 Thermochemical process renewable fuel production

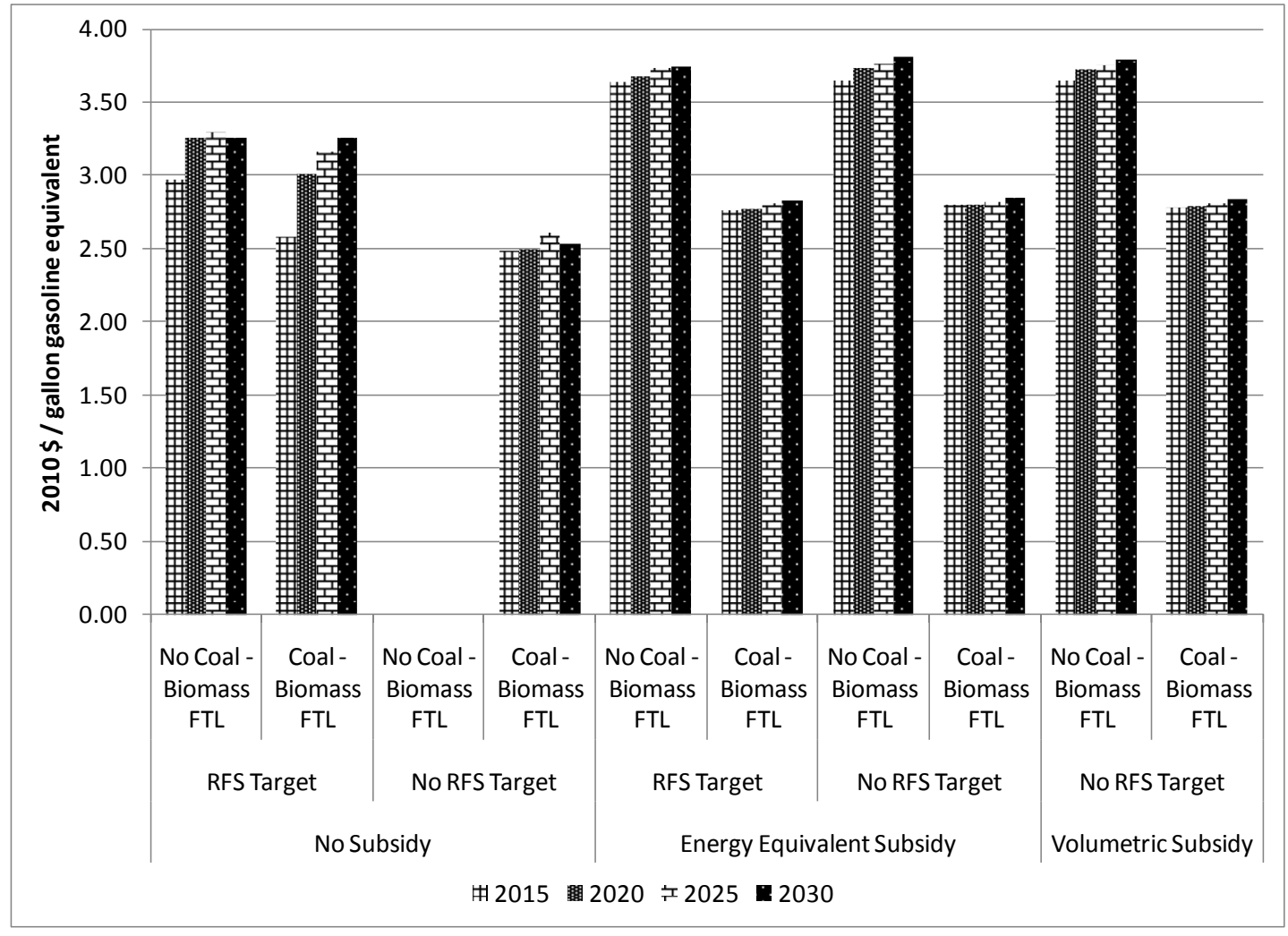

Figure 10 Prices for thermochemical fuels 
Figure 11 contains total cellulosic biofuel production. With no RFS, no subsidy, and biomass only technology, there is no cellulosic biofuel. If coal technology is enabled, there is a tiny level of biofuel production. With the RFS in place, the full 16 bil. gal. ethanol equivalent is produced. With no RFS but either an energy equivalent or volumetric subsidy, production ranges between 8 and 13 bil. gal. depending on which subsidy is operative and what technology is employed.

Figure 12 contains the implicit tax/subsidy for the cellulosic RFS over time and under assumption of biomass only and biomass plus coal technologies being employed. The RFS is essentially a variable tax on consumers and subsidy to producers of corn ethanol with the amount of the tax/subsidy depending on the price of the fossil alternative and the others renewable fuels available in the market. The implicit tax/subsidy varies between 7 cents to $\$ 1$ per gallon of ethanol equivalent biofuel depending on what alternative technologies are available, the oil price, and corn cost. With only biomass, required subsidy level starts up from 50 cents stabilizes around 80 cents between 2020 and 2030. With coal/biomass option, initial shadow price starts from 7 cents which is very close zero, but due to mainly increasing coal prices required subsidy levels increases faster than thebiomass only option, and 92 cents per gallon ethanol equivalent subsidy is needed to achieve the RFS target in the 2030 period.

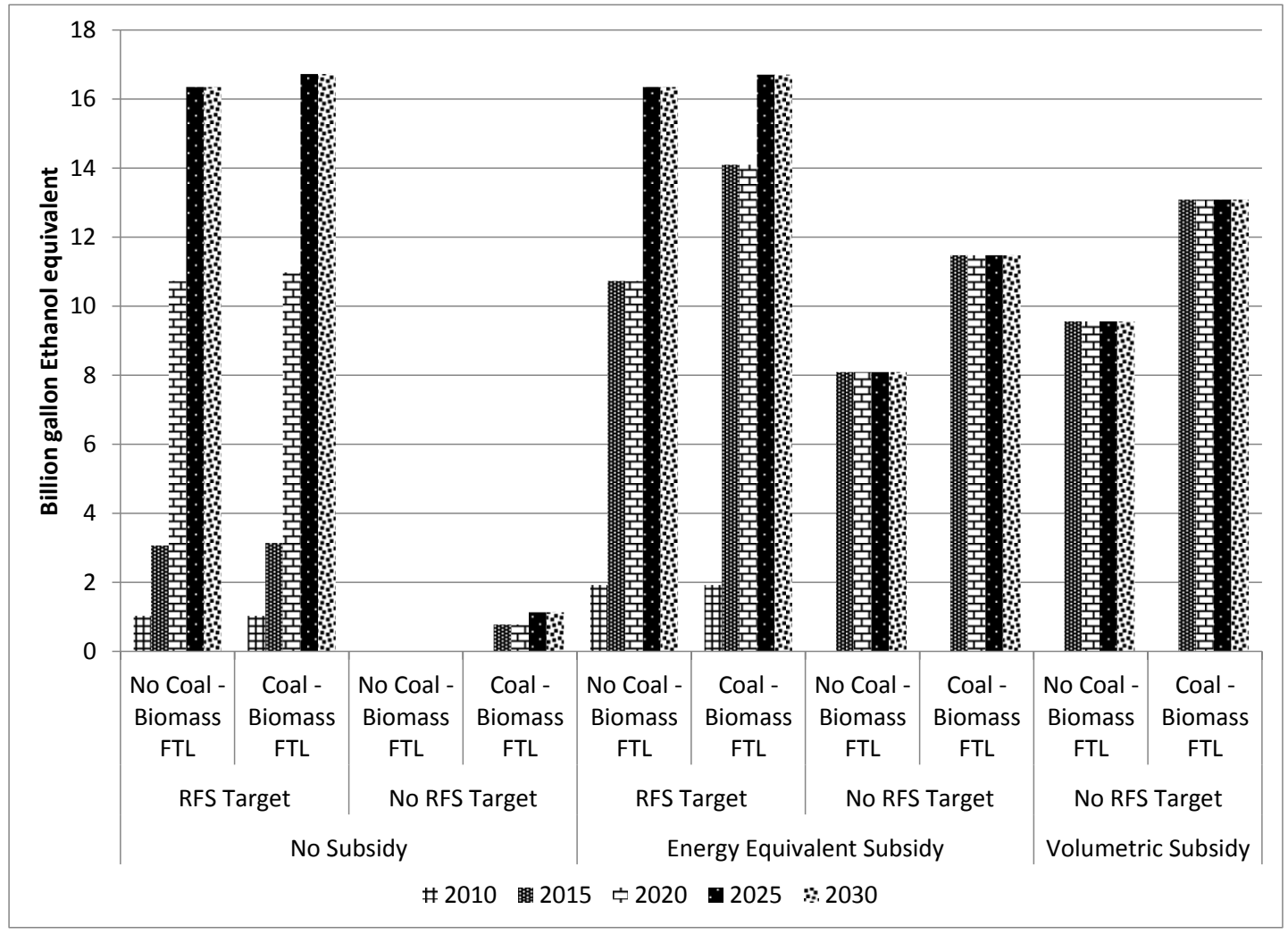

Figure 11 Total cellulose biofuel production 


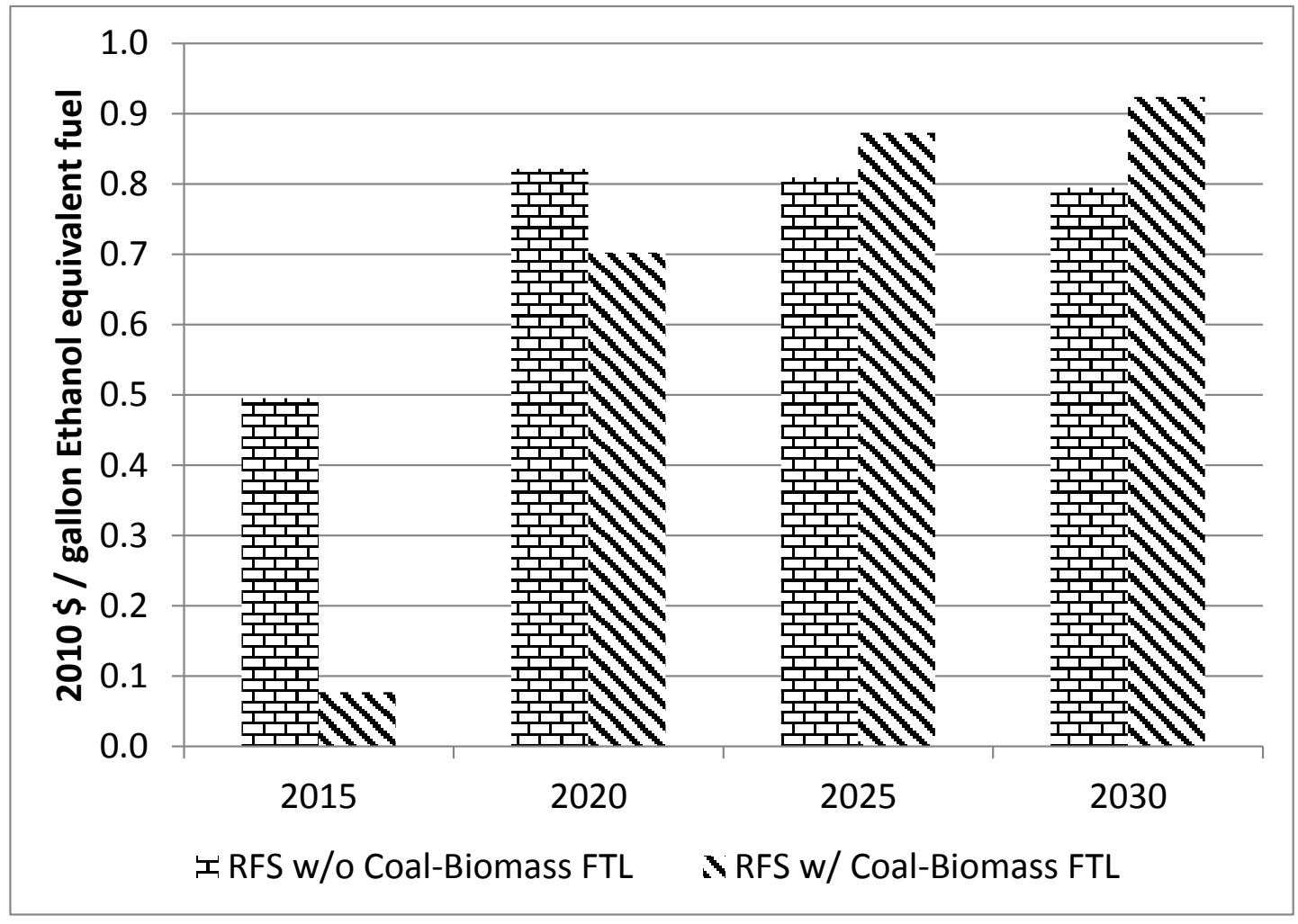

Figure 12 Cellulosic biofuel RFS target shadow prices (required subsidies to reach target)

\subsubsection{Cellulosic feedstock use}

In this version of the model, we have corn stover, switchgrass and miscanthus feedstocks enabled. The feedstocks can be used in either biochemical or thermochemical production processes. Corn stover is limited to the stover deemed to be available with sustainable removal. Corn stover is less expensive than switchgrass / miscanthus in this analysis. Figures 13 and 14 show the corn stover use for biochemical and thermochemical production respectively. Clearly, most of the stover gets used for thermochemical production under most scenario assumptions. 


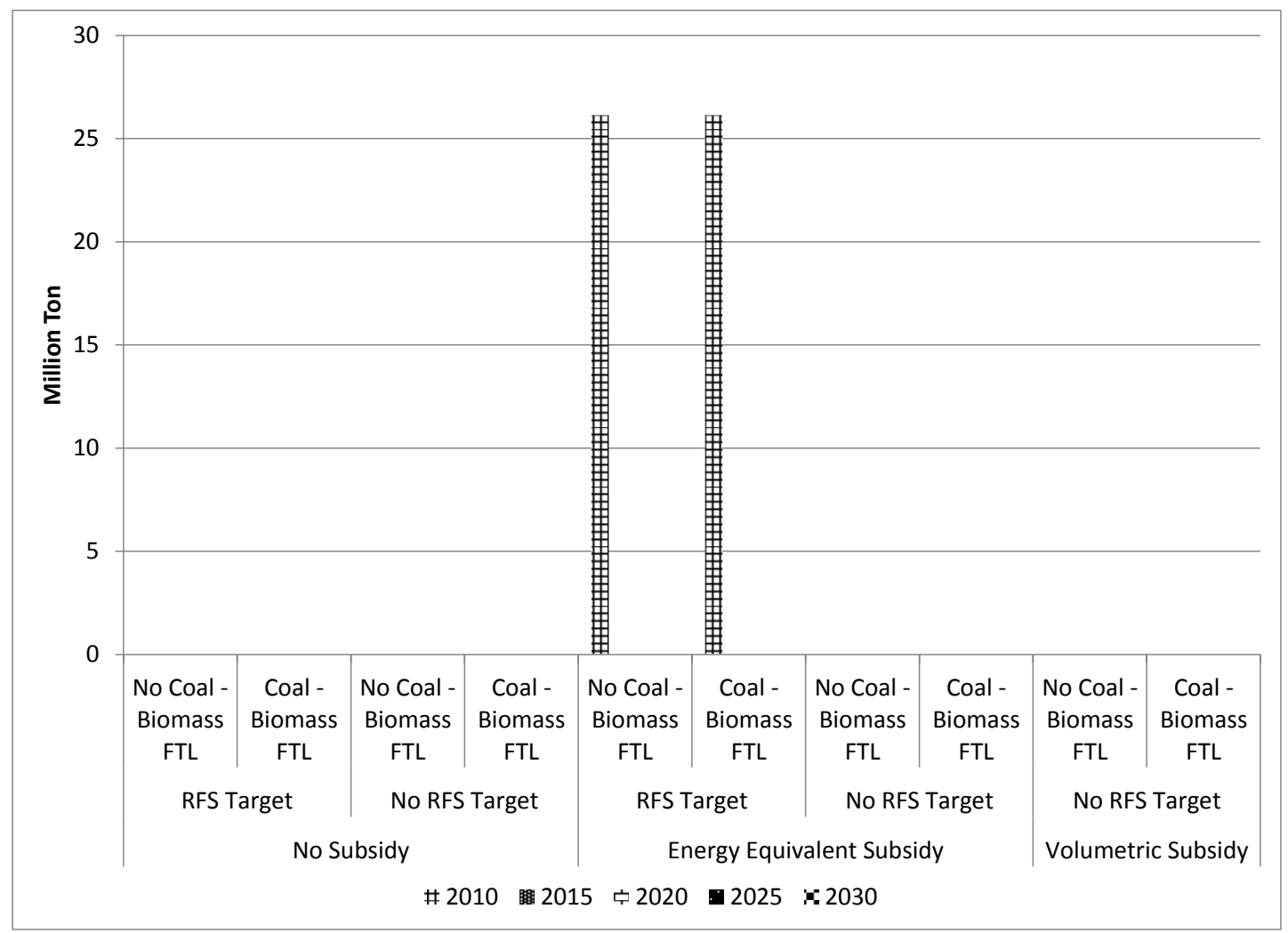

Figure 13. Stover use for the biochemical process

Miscanthus and switchgrass are used in these simulations only for the RFS cases, both for biochemical and thermochemical production pathways. In those cases, the corn stover supply is exhausted and more biomass feedstock is needed to meet the RFS, so the model turns to switchgrass / miscanthus. 


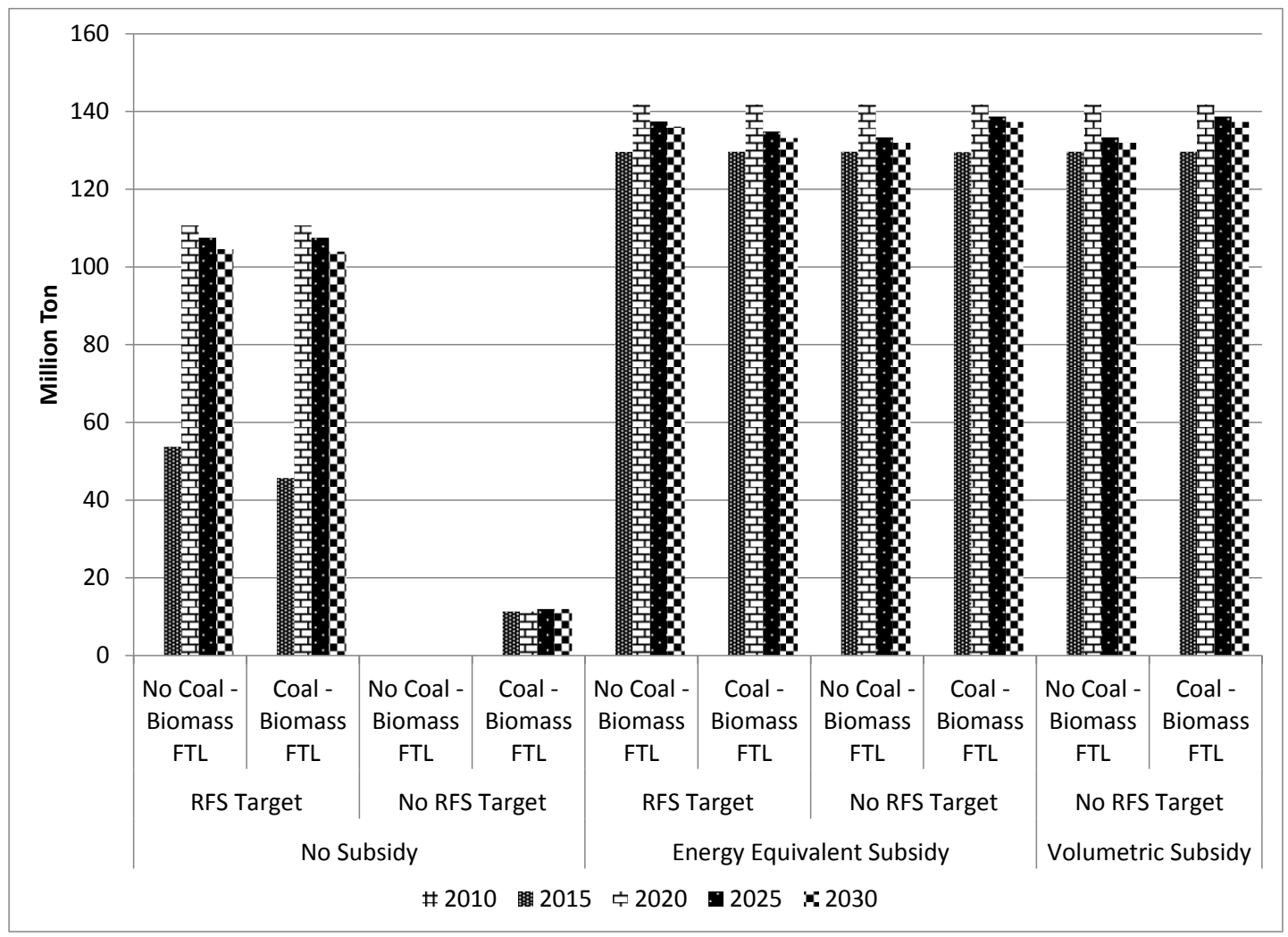

Figure 14 Stover use for thermochemical processes

\subsubsection{Policy costs}

Clearly these results indicate that the biofuels industry is driven by government policy and given what is projected to develop for the technologies over the next two decades that will continue to be the case. Figure 15 provides total system cost increases (\$/gal. ethanol equivalent) due to the combined RFSs. Results are provided with and without coal/biomass technology enabled. With biomass only technology, the system cost increases from 40 to 65 cents per gallon of ethanol equivalent ( $\$ 0.6$ to $\$ 0.98$ per gallon of gasoline equivalent) due to the existence of the RFS. With coal/biomass technology enabled, this cost changes to 38 to 55 cents per gallon of ethanol equivalent. Clearly use of coal in combination with biomass could reduce the renewable fuel cost.

Figure 16 provides the total system costs increase for corn ethanol biofuels. The cost increase ranges from $\$ 0.12$ to $\$ 0.35$ for biomass only and similar for the coal/biomass combination with the exception of period 2020 where the average cost with coal is 11 cents lower. Coal/biomass combination reduces cost and the variation in cost due to complimentary nature of products in the system.

Figure 17 provides the total system costs increase (compared to only corn ethanol production case alone) for cellulosic biofuels. The cost increase ranges from $\$ 0.48$ to $\$ 0.80$ for biomass only and from $\$ 0.48$ to $\$ 0.82$ for the coal/biomass combination over the 2020 to 2030 period. After period 2015, the scenario with coal/biomass thermochemical pathway is cost effective compared to the scenario with only biomass thermochemical pathway. This may be thought as delayed refinery investments, required equipment changes, since the produced fuels do not require any change in technology present in the system.

Thermochemical fuels are "drop-in" requiring no significant infrastructure changes. In period 2015 higher average cost of coal biomass thermochemical scenario is due to the higher investment cost needed due to per liter renewable biofuel production. Only $43 \%$ of the coal/biomass FTL technology is accounted as renewable biofuel. 


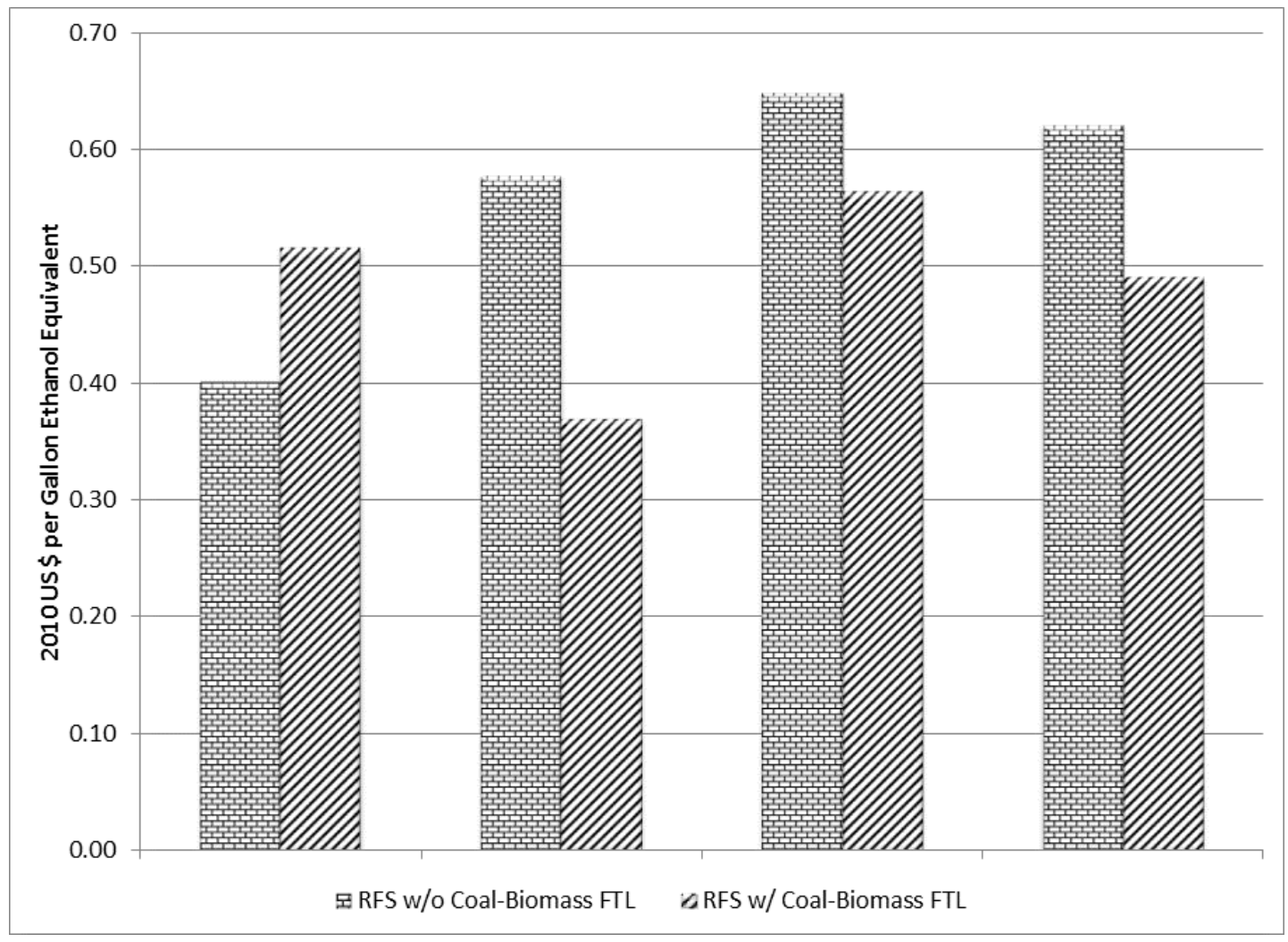

Figure 15 Total system cost increase per gallon ethanol equivalent fuel due to RFS targets

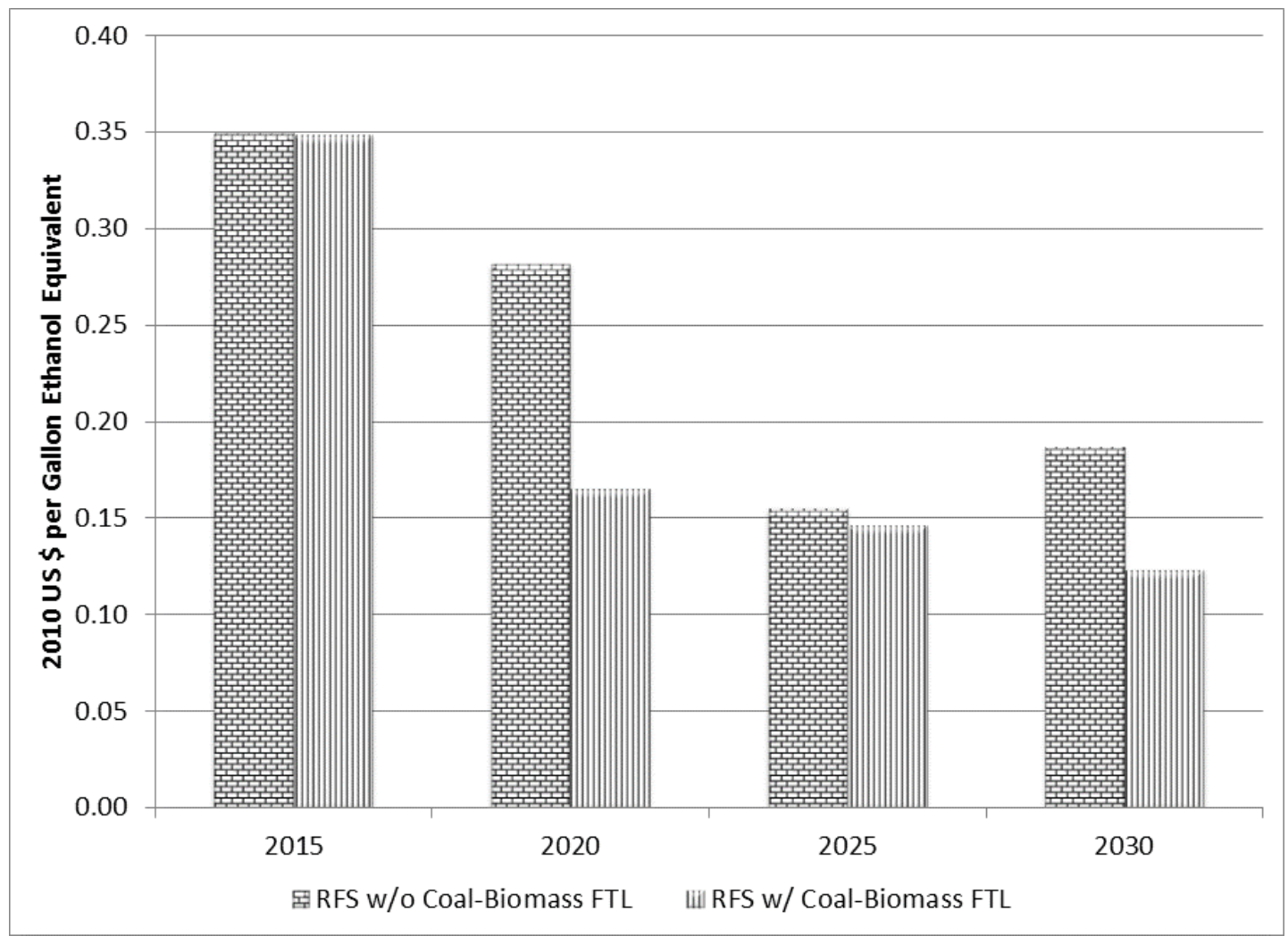

Figure 16 Total System Cost Increase per Gallon of Corn Ethanol Produced 


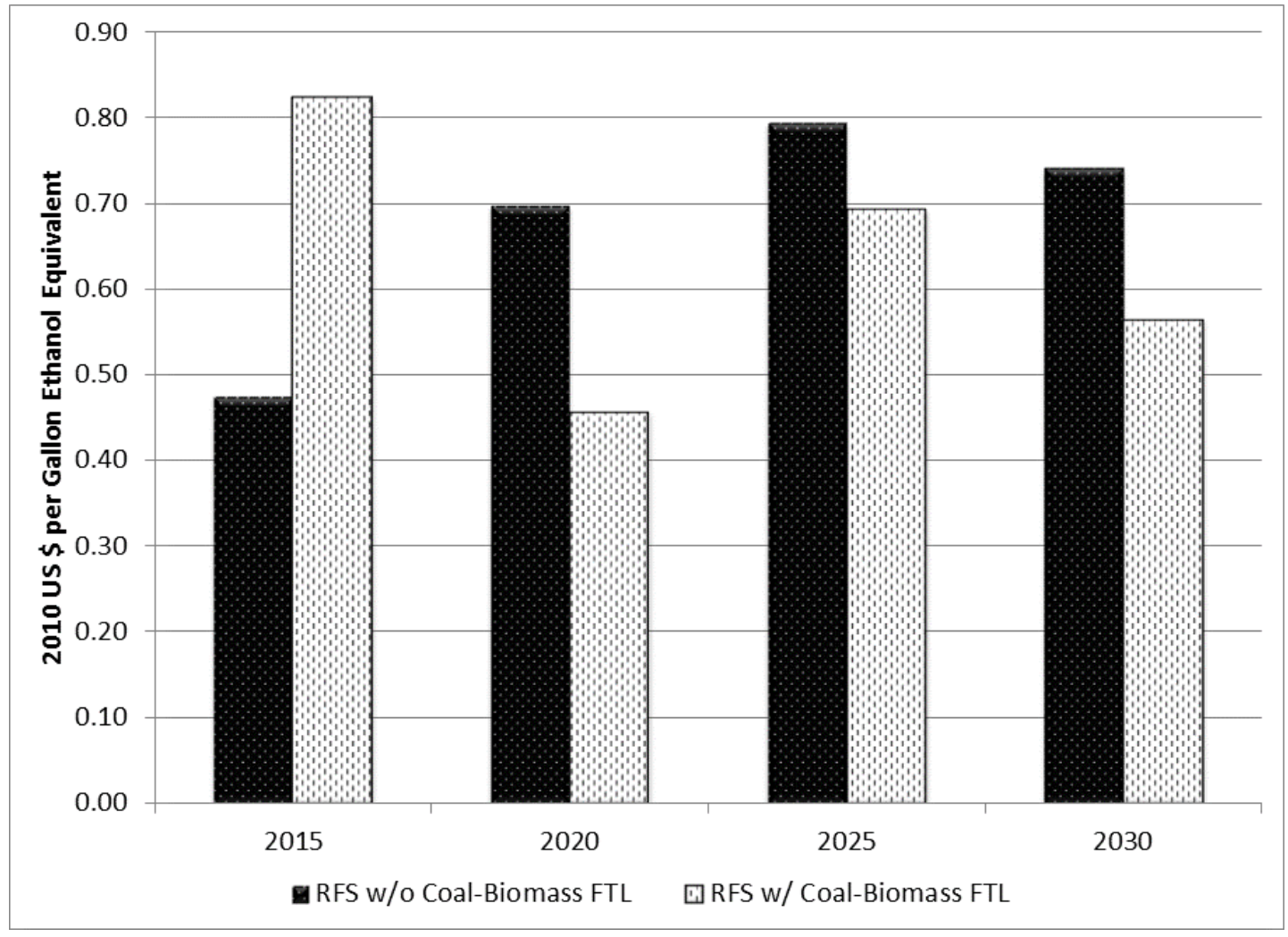

Figure 17 Total System Cost Increase per Gallon of Cellulosic Biofuel Produced

Figure 18 provides the total annual system costs per gallon of equivalent gallon ethanol under alternative policy sets and technologies. The system cost ranges between about $\$ 0.30$ and $\$ 0.60$ over the years 2015 to 2030 depending on the policy set for only biomass thermochemical pathway. This cost range drops down to $\$ 0.23$ and $\$ 0.62$ range with coal/biomass thermochemical pathway. This demonstrates the importance and cost effectiveness of the technological option.

Figure 19 provides the total annual system subsidy costs under alternative policy sets and technologies. The subsidy costs ranges between about $\$ 8.5$ bil. and $\$ 18.5$ bil. over the years 2015 to 2030 depending on the policy set. Coal/biomass thermochemical pathway increases the total subsidy cost due to increased output. Volumetric subsidy policy increases the subsidy costs considerably due to the higher level of biofuel output. 


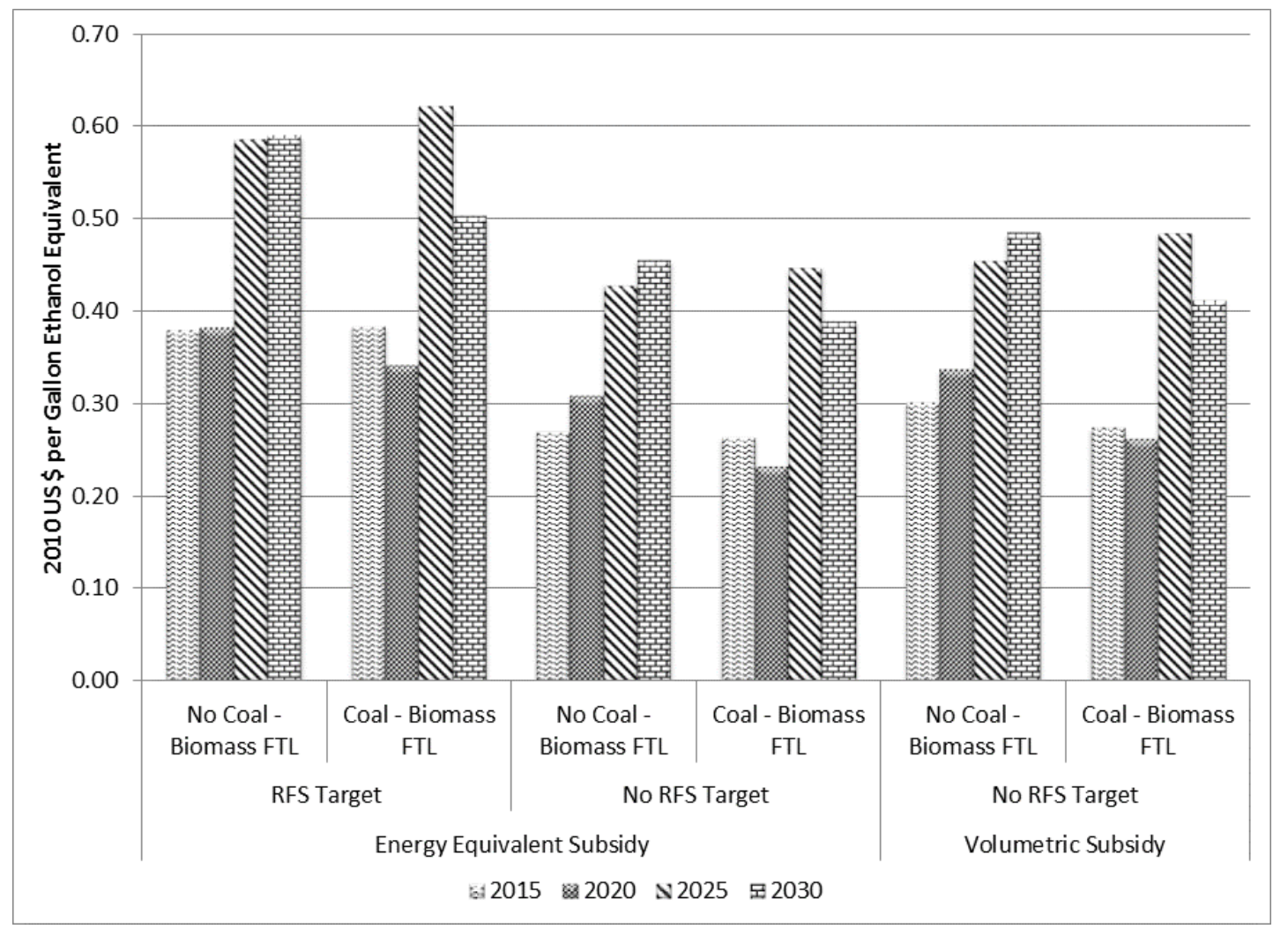

Figure 18 Total system cost increase for each gallon biofuel under alternative policy sets

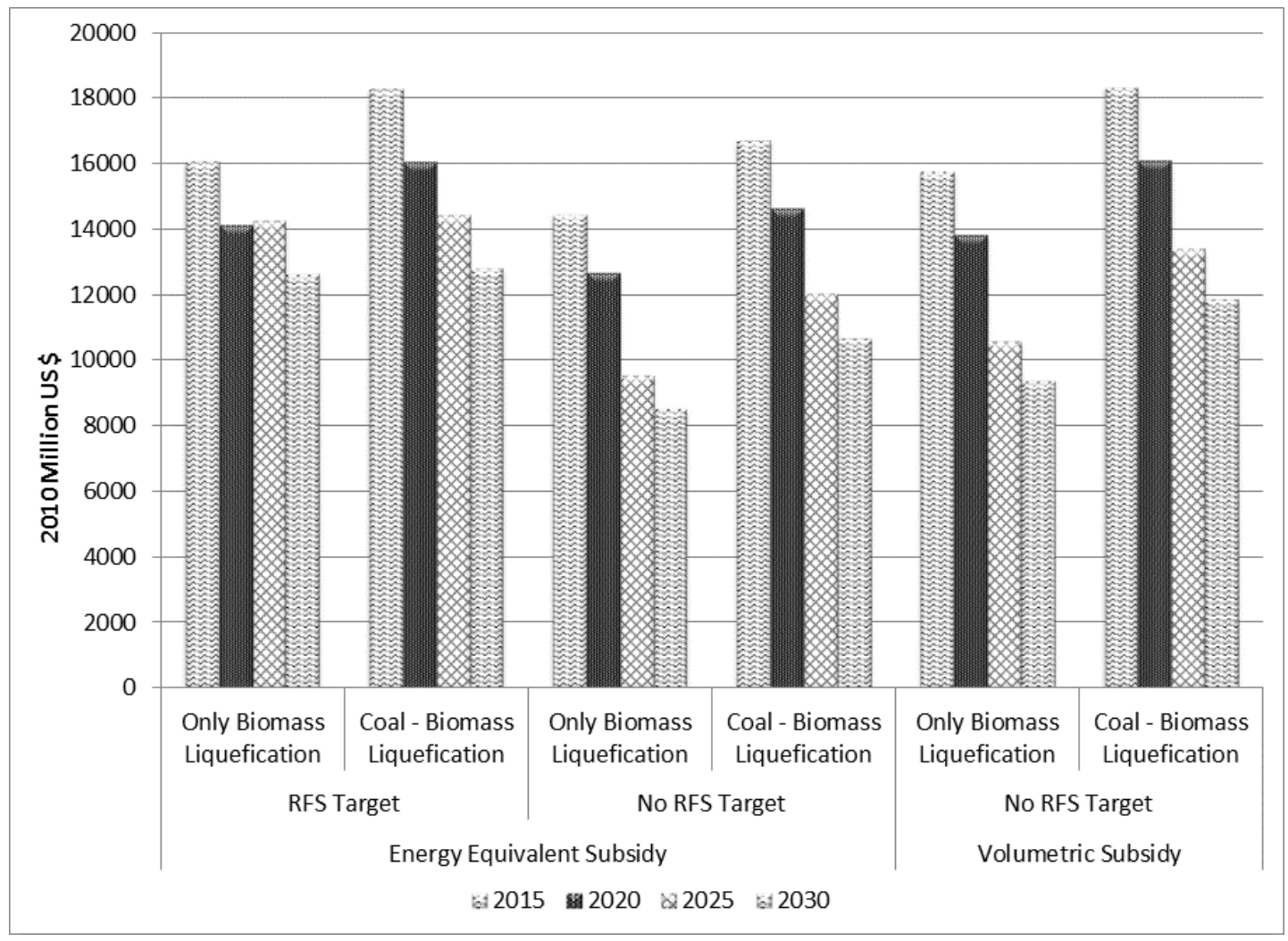

Figure 19 Total system cost increase under alternative policy sets 


\section{Conclusions}

In this research we have modified the standard US MARKAL model to include a land resource base, to include corn stover and miscanthus feedstocks, and to include new cost information for biochemical and thermochemical conversion technologies. We then used this revised MARKAL model to estimate the impacts of five different policy options and technology choice sets:

1. No government interventions in biofuel markets (no RFS and subsidies)

2. Biofuels RFS targets are implemented.

3. Biofuel subsidies only are implemented based on current legislation. Currently, the corn ethanol subsidy is 45 cents per gallon, and the cellulose biofuel subsidy (regardless of what biofuel) is \$1.01/gal. This scenario tests subsidies on a volumetric basis as at present (\$/gal.).

4. The subsidy in this case is based on energy content instead of volume. Cellulosic ethanol has a subsidy of $\$ 0.67$, whereas cellulosic bio-gasoline is at $\$ 1.01 / \mathrm{gal}$. Corn ethanol remains at $\$ 0.45 /$ gal.

5. The fifth scenario is a combination of the RFS and the energy equivalent subsidies. (2 and 4).

We also evaluated all policy choices with biomass only and coal/biomass feedstocks.

The results clearly demonstrate that the biofuels industry is driven by government policy. Some of the major conclusions are as follows:

- Little or no biofuels would be produced in the absence of the RFS and all subsidies. Some corn ethanol would be produced without RFS or subsidies, but less than current production.

- No cellulosic biofuels would be produced without government incentives.

- Production of cellulosic ethanol is not attractive even under the volumetric subsidy regime.

- The subsidy costs vary widely depending on the subsidy used and whether or not the coal/biomass technology is enabled.

- Coal combined thermochemical pathway with biomass is cheaper than biomass alone (by about $\$ 1 /$ gal. gasoline equivalent).

- The subsidy costs and costs of the RFS also vary depending on what is happening with development of other energy technologies. Quantification of this effect is possible only with a bottom up energy model like MARKAL.

We have demonstrated that the standard MARKAL results can be considerably enhanced by combining richer information on the land supply data from GTAP into MARKAL. Indeed, without use of this land supply data, MARKAL and other energy models cannot reliably be used for biofuels economic and policy analysis.

Acknowledgement: This research was funded by the National Institute for Food and Agriculture, U.S. Department of Agriculture. 


\section{References}

Abbott P, Hurt C, Tyner W, 2008. What's Driving Food Prices? Farm Foundation Issue Report.

Abbott P, Hurt C, Tyner WE, 2009. What's Driving Food Prices? March 2009 Update, Farm Foundation Issue Report.

Carol Shay, DeCarolis J, Loughlin D, Gage C, Sonia Yeh, Wright EL, 2006. EPA US National MARKAL DATABASE.

Dimaranan BV, 2006. Global Trade, Assistance, and Production: The GTAP 6 Data Base., in: Analysis CfGT (Ed.).

Purdue University, West Lafayette, IN.

$\mathrm{Hu} \mathrm{M}, \mathrm{Hobbs} \mathrm{B}$. Analysis of multi-pollutant policies for the US power sector under technology and policy uncertainty using MARKAL. Energy 2010.

Kreutz T, Larson E, Liu G, Williams R, 2008. Fischer-Tropsch fuels from coal and biomass, 25th Annual International Pittsburgh Coal Conference.

Lee H-L, Hertel TW, Sohngen B, Ramankutty N, 2005. Towards and Integrated Land Use Data Base for Assessing the Potential for Greenhouse Gas Mitigation, in: Center for Global Trade Analysis (Ed.), GTAP Technical Paper \# 25. Purdue University, West Lafayette, IN.

National Academy of Sciences NAoE, and National Research Council of the National Academies. Liquid Transportation Fuels from Coal and Biomass: Technological Status, Costs, and Environmental Impacts: Washington, DC; 2009.

Sauthoff A, Meier P, Holloway T. CFIRE 02-10 April 2010. 2010.

Schafer A, Jacoby $\mathrm{H}$. Vehicle technology under $\mathrm{CO} 2$ constraint: a general equilibrium analysis. Energy Economics 2006;34; 975-985.

Tyner WE. The US Ethanol and Biofuels Boom: Its Origins, Current Status, and Future Prospects. BioScience 2008;58; 646-653.

Tyner WE, Dooley F, Viteri D. Alternative Pathways for Fulfilling the RFS Mandate. American Journal of Agricultural Economics 2010a;92.

Tyner WE, Taheripour F. Policy Options for Integrated Energy and Agricultural Markets. Review of Agricultural Economics 2008;30; 387-396.

Tyner WE, Taheripour F, Perkis D. Comparison of Fixed Versus Variable Biofuels Incentives. Energy Policy 2010b;38; 5530-5540. 